\title{
One set of sounds, two tonotopic maps: exploring auditory cortex with amplitude-modulated tones
}

\author{
N. Weisz*, A. Keil, C. Wienbruch, S. Hoffmeister, T. Elbert \\ Department of Psychology, University of Konstanz, Box D25, D-78457 Konstanz, Germany
}

Accepted 30 December 2003

\begin{abstract}
Objective: The possibility of simultaneously observing activation of primary and secondary auditory cortices has been demonstrated by Engelien et al. [Hear Res 2000;148:153-60].

Methods: Such a dual monitoring by means of neuromagnetic recordings can be achieved when a subject is stimulated by brief pulses of $40 \mathrm{~Hz}$-modulated tones. Depending on the frequency filter applied, either the steady-state field (SSF) or the N $1 \mathrm{~m}$ can be extracted from the evoked magnetic field complex.

Results: Using this 'combined' (two-maps) paradigm with 4 carrier frequencies, we show that it is possible to synchronously screen two tonotopic maps- one map each reflected either by the SSF or the N $1 \mathrm{~m}$. Indicators are the systematic variation in the location (higher frequencies are more posterior) and orientation (higher frequencies oriented differently in the saggital plane) of the equival ent current dipole (ECD). These parameters were compared with those obtained from 'classic' (one map) paradigms in which either a pure tone elicits an $\mathrm{N} 1 \mathrm{~m}$ or a $40 \mathrm{~Hz}$ continuous ( $3 \mathrm{~s}$ ) stimulation produces an SSF. Overall the results were similar, however, systematic differences between the paradigms were found for ECD localization, dipole strength, amplitude, and phase.

Conclusions and Significance: One possible interpretation of these results is that different tonotopically arranged cortical fields were involved in the generation of the components.

(C) 2004 International Federation of Clinical Neurophysiology. Published by Elsevier Ireland Ltd. All rights reserved.
\end{abstract}

Keywords: Tonotopy; N1m; Steady-state field; M agnetencephalography; M agnetic source imaging

\section{Introduction}

From both animal (Kaas et al., 1999; Merzenich et al., 1975) and human studies (Pantev et al., 1993, 1996; Romani, 1986; Romani et al., 1982a,b) it is well-known that neurons in the auditory cortex are arranged tonotopically (i.e. frequency-specific), thus resembling the spatial order of the inner hair cells on the basilar membrane. However, speaking of the tonotopic organization of the auditory cortex can be misleading. The auditory cortex can be divided into several areas, each comprising multiple subareas. Each subarea exhibits tonotopy to a varying degree and manner (Rouiller, 1997). A ccording to K aas et al. (1999) the main hierarchically organized areas in primates are the core (including the primary auditory field, Al), the

\footnotetext{
* Corresponding author. Tel.: +49-7531-88-4606; fax: +49-7531-884601.

E-mail address: nathan.weisz@ uni-konstanz.de (N.W eisz).
}

belt and the parabelt, out of which the core can be considered the actual primary auditory cortex. The different areas of the core show the highest tonotopic order with an either anterior/anterolateral to posterior/posteromedial or directly opposite gradient depending on the field (see also Ehret, 1997).

So far, magnetencephalography (MEG) has proven to be a successful non-invasive technique to study the tonotopic organization of the auditory cortex in humans. The standard MEG approach to investigate tonotopy consists of source localization of the $\mathrm{N} 1 \mathrm{~m}$ (operationalized as a single equival ent current dipole (ECD) in a homogeneous sphere) elicited by pure tones of a few hundred milliseconds duration with varying frequency. Although, the first study (Romani et al., 1982a,b) to non-invasively demonstrate tonotopy in man used steady-state stimuli, such attempts have been scarce (Pantev et al., 1996). Typical auditory steady-state stimuli are amplitude- or frequency-modulated tones. Initial perturbations of the signal can be discarded if 
the stimuli are sufficiently long (seconds to minutes). Typically a modulation rate of $35-40 \mathrm{~Hz}$ is chosen in order to obtain maximum response energy (G alambos et al., 1981; Hari et al., 1989; Pastor et al., 2002; Roß et al., 2000).

In the following, we will refer to these two conventional approaches (i.e. elicitation of the $\mathrm{N} 1 \mathrm{~m}$ by pure tones and the steady-state field (SSF) by continuous $40 \mathrm{~Hz}$ modulated tones) as classic paradigms. They are differentiated from a combined paradigm, a term introduced by Engelien et al. (2000). It refers to the possibility of extracting the transient $\mathrm{N} 1 \mathrm{~m}$ - and the steady-state response to the same stimulus, which has been first shown by $M$ äkelä and Hari (1987). A simultaneous- and thus time-economic- measurement of both components is desirable, since sources for these components are associated with activations from primary or secondary auditory cortex, respectively (see below). Engelien et al. raised the question whether the N $1 \mathrm{~m}$ and SSF gained at the same time via the combined approach would lead to identical source localizations as if assessed by the classic approach. These authors presented a pure tone with a carrier frequency of $250 \mathrm{~Hz}$ and a duration of $500 \mathrm{~ms}$ for elicitation of the $\mathrm{N} 1 \mathrm{~m}$, and a continuous $200 \mathrm{~s} 39 \mathrm{~Hz}$ amplitude-modulated tone was used for elicitation of the SSF, thus representing classic paradigms. A third-combined-paradigm presented the same carrier frequency as $500 \mathrm{~ms} 39 \mathrm{~Hz}$ amplitudemodulated tones, thus combining features of both aforementioned paradigms, in order to gain the N $1 \mathrm{~m}$ and SSF simultaneously. The authors demonstrated that the components obtained simultaneously and their classcial counterparts (a) showed the same pattern of differences and (b) seemed not to differ in location. How ever, only one single carrier frequency was used, i.e. no information was obtained with respect to tonotopy. The main goal of the present study was to see if and which tonotopic maps can be obtained by using the combined paradigm described above on 4 different carrier frequencies.

In the past, 3 neuromagnetic measures served as indicators for the presence of tonotopically arranged neuronal populations (fields) in the auditory cortex in humans: (a) change of the location of a component as a function of the frequency of the eliciting stimulus, (b) spatial separation of tonotopic gradient in dependence of the component investigated, and (c) orientation of the dipole.

\subsection{Direction of tonotopic gradient}

For the N1m some authors have found a low-to-high frequency-specific arrangement of ECD sources on the anterior-posterior axis (Elberling et al., 1982). However, the great majority of MEG studies localize the main tonotopic gradient on a medial-lateral axis (Elbert et al., 2002; Lütkenhöner and Steinsträter, 1998; Pantev et al., 1993) with the depth of the source linearly increasing with the logarithm of the carrier frequency. Those studies investigating SSF have also reported tonotopy for high-to-low frequencies in the medial-lateral direction (Pantev et al., 1996; Romani et al., 1982a,b; Roß et al., 2000). While the SSF map seems consistent with primate studies (Kaas et al., 1999), BOLD imaging in humans confirms the significance of the spatial gradient for the $\mathrm{N} 1 \mathrm{~m}$ showing that the center of activation shifts in a posterior and medial directions for higher frequencies ( $L$ auter et al., 1985; Wessinger et al., 2001).

\subsection{Spatial separation of tonotopic gradient in dependence} of the component

A lthough the direction of the tonotopic gradient seems to be the same for the N1m and SSF, ECD sources have significantly different locations, thus suggesting that different areas of the auditory cortex may be activated. In comparison to the $\mathrm{N} 1 \mathrm{~m}$, which has been associated with activation of the secondary auditory cortex and lateral parts of Heschl's gyrus (Godey et al., 2001; Lütkenhöner and Steinsträter, 1998), sources for SSF seem to be located more anterior and more medial and have been related to activation of the primary auditory cortex (Engelien et al., 2000; Pantev et al., 1996; Tiihonen et al., 1989). Overall, data from neuromagnetic studies confirm that the human auditory cortex-like the one in primates-can be subdivided into different tonotopically arranged fields. This view is supported by recent fMRI (Talavage et al., 2000) and post-mortem histochemical studies (W allace et al., 2002). However, the exact number of different fields in human auditory cortex remains a matter of controversy (Talavage et al., 2000).

\subsection{Dipole orientation in the saggital plane}

For the N1m, some authors reported a systematic relationship between frequency and dipole orientation (Tiitinen et al., 1993; Verkindt et al., 1995). Generally, when viewed from the lateral surface in the saggital plane, the angle in the right hemisphere rotates clockwise with increasing frequency of the stimulus. According to Verkindt et al. (1995) this might be due to gyral folding characteristics varying with depth. Tiitinen et al. (1993) were able to show the same pattern for the Mismatch Negativity. To the best of our knowledge, no work has yet investigated whether such an association between dipole orientation and frequency also exists for the SSF.

According to the criteria mentioned above dipole localizations on two of the 3 coordinate axes (posterioranterior, medial-lateral) and dipole orientation in the saggital plane served as indicators of tonotopy. Sources of the $\mathrm{N} 1 \mathrm{~m}$ and SSF were regarded as activations from different auditory fields if they were separable in space. The results from the combined paradigm were compared to results obtained with the classic paradigms to elicit an $\mathrm{N} 1 \mathrm{~m}$ and an SSF. We compared the following dependent variables: localization on the 3 coordinate axes, dipole 
orientation, dipole strength $(Q)$, peak amplitude and peak latency/phase (in case of the N Im or SSF, respectively).

\section{Methods}

\subsection{Subjects}

Eleven right-handed participants ( 6 females; age range 20- 28 years) without neurological or otological disorders gave informed consent after obtaining written and oral information on the nature of the study. They received $€ 15$ for participation.

\subsection{Neuromagnetic recording}

Neuromagnetic data were recorded (A/D conversion rate: $678.17 \mathrm{~Hz}$; $0.1-200 \mathrm{~Hz}$ bandpass) with a 148 channel whole-head magnetometer (4D Neuroimaging Inc., San Diego, CA). Vertical and horizontal electro-oculogram (EOG) were measured from above and below the eye and from the outer canthi in order to reject epochs contaminated by eye-movements and eye-blinks. These were identified by amplitudes exceeding $100 \mu \mathrm{V}$.

\subsection{Procedure}

A uditory stimuli were monaurally presented via a plastic tube attached to an earpiece in the left ear of the participant. Individual sensation levels (SL) were assessed prior to the MEG-measurement for each frequency-stimulus type combination. Sounds were presented at an intensity of $50 \mathrm{~dB} \mathrm{SL}$. During the neuromagnetic recording session, subjects laid in a supine position watching a film of their choice which was projected to the ceiling of the magnetically shielded room.

We used 4 carrier frequencies of 1000, 1817, 3302 and $6000 \mathrm{~Hz}$ which were presented blockwise in 3 different manners:

1. N1m-classic paradigm: Pure tones of $500 \mathrm{~ms}$ duration (5 ms rise and fall time; 200 stimuli; SOA varying between 1500 and 2500 ms); component of interest: N 1m; presumed activation from secondary auditory cortex.

2. SSF-classic paradigm: A mplitude-modulated tones of $3 \mathrm{~s}$ duration (50 stimuli; SOA varying between 4000 and $4500 \mathrm{~ms}$ ). M odulation rate was $39 \mathrm{~Hz}$, modulation depth was $100 \%$; component of interest: SSF; presumed activation from primary auditory cortex.

3. Combined paradigm: A nalogous to SSF-classic, except that duration was shortened to $500 \mathrm{~ms}$ (200 stimuli; SOA varying between 1500 and $2500 \mathrm{~ms}$ ). The N $1 \mathrm{~m}$ and the SSF can be extracted from the compound-evoked magnetic field by different digital bandpass filters; presumed activations from primary and secondary auditory cortices.

\subsection{Data analysis}

N Im was analyzed in the N1m-classic and the bimapping conditions. For this purpose a time-window ranging from $150 \mathrm{~ms}$ before and $300 \mathrm{~ms}$ after stimulus onset was selected. A rtefact free epochs were averaged and filtered with a 1-20 Hz digital bandpass (Butterworth characteristic of 2 nd order). For each subject a group of 38 magnetic sensors was determined over the right hemisphere that both, covered well the evoked magnetic fields and could best explain the observed magnetic fields. $\mathrm{M}$ agnetic source imaging ( $\mathrm{MSI}$ ) was performed for each of the 12 runs. We used a homogeneous sphere as volume conductor, which fitted best the subjects head underneath the selected sensor in a least square sense. Single ECD were fitted for each sampling point $10 \mathrm{~ms}$ before and $4 \mathrm{~ms}$ after the peak of the N1m. A median was calculated from those resulting sources with a minimum goodness- of-fit (GOF) of 0.90 or better.

The SSF-classic and the bi-mapping paradigms were designed to produce a $39 \mathrm{~Hz}$ oscillatory SSF. Hence data were filtered with a 37-41 Hz digital bandpass (B utterworth characteristic 2nd order) and split into epochs of $102 \mathrm{~ms}$ following stimulus onset. The first and last epochs of the stimulus, i.e. from 0 to $102 \mathrm{~ms}$ after stimulus onset and 102 ms before stimulus offset were excluded from further analysis. Thus approximately 1370 (in the case of SSFclassic) or 580 epochs (in the case of SSF-combined) entered the averaging procedure for the respective paradigm. As for the N1m-analysis a sensor group was determined for every subject. The resulting ECD sources for every time point were arranged according to their GOF and the best 3 fits were accepted if their localizations met the following criteria: a posterior - anterior range from 0 to $4 \mathrm{~cm}$ and medial - lateral not more positive (meaning further towards left) than $-2 \mathrm{~cm}$. These additional criteria were included, as the GOF for the SSF ( $M=0.87$, SD 0.05) was approximately $10 \%$ lower than the one for the $\mathrm{N} 1 \mathrm{~m}$ ( $M=0.97, \mathrm{SD} 0.01)$, independent of paradigm or carrier frequency.

As indicators of tonotopy we chose source localization on the medial-lateral ( $y$-axis) and posterior-anterior ( $x$-axis). Furthermore dipole orientation in the saggital plane was investigated using the following formula:

angle(degrees) $=\operatorname{atan}\left(Q_{z} / Q_{x}\right) / \pi \times 180$,

where $Q_{z}$ and $Q_{x}$ are the projections of the dipole moment in the inferior-superior $\left(z^{-}\right)$and posterior-anterior $(x-)$ directions, respectively. The major interest was to see whether two tonotopic maps could be obtained simultaneously. A nother goal was to determine whether the different approaches (i.e. classic vs. combined) for the components would produce similar results. Comparisons were made in terms of the ECD results (position, strength, orientation) but also on measures of the waveform (amplitude and latency/phase). Statistical analysis was 
accomplished with analysis of variance (ANOVA) for repeated measurements. In the case of significant results $(P<0.05)$ of the ANOVA the Tukey-Kramer procedure was applied for post-hoc analysis. In order to analyze the $39 \mathrm{~Hz}$ steady-state signal in terms of amplitude and phase, however, a different approach was chosen as the knowledge about the specific frequency content can be employed. A veraged data were first projected into source space (197 sources) by means of the minimum-norm estimate $(M N E)$, a linear estimation technique first introduced by Hämäläinen and IImoniemi (1984). 197 dipole locations, evenly spaced on a spherical shell $(60 \%$ of radius of the fitted sphere), were used as source space (H auk et al., 2002). Each location consisted of two perpendicular dipoles oriented tangentially to the shell surface. An FFT was then performed over the entire source space activity. The resulting complex values for the $39 \mathrm{~Hz}$ activity of every participant were sorted into different arrays according to the conditions. These arrays were submitted to circular $\mathrm{T}^{2}$ algorithm (Victor and Mast, 1991), which is sensitive to differences between samples of complex Fourier values reflecting oscillatory activity in different experimental conditions. To illustrate the contributions of $39 \mathrm{~Hz}$ FFT amplitude and phase to the $\mathrm{T}^{2}$ effects observed, we used a planned comparisons approach. Previous studies (e.g. Roß et al., 2000) demonstrated a negative relationship between carrier frequency of the stimulus and amplitude or phase of the auditory SSF. Therefore we reduced the 24 difference maps reflecting all possible pairwise comparisons to 4 maps ( 2 paradigms $\times 2$ dependent variables). To this end we used linear contrasts for repeated measurements (R osenthal and Rosnow, 1985). These were computed at each dipole location of L2-norm solution space, delineating the statistical significance and effect size of the hypothesized relationship stated above, namely a linear decrease of phase and amplitude as a function of carrier frequency. More details are given in Section 3.

\section{Results}

\subsection{N1m peak latency}

From N 1m waveforms depicted in Fig. 1a it can be seen that the $\mathrm{N} 1 \mathrm{~m}$ deflections peaked at approximately $100 \mathrm{~ms}$. However, for the combined paradigm they showed a consistent delay of about $7 \mathrm{~ms}$ for all the frequencies ( $M=104.54 \mathrm{~ms}$, SE 1.62) compared to their counterparts derived from the classic paradigm $(M=97.47 \mathrm{~ms}$, SE 1.64; $\left.F_{1,10}=46.66, P<0.001\right)$. A significant effect on latency was found for the factor frequency $\left(F_{3,30}=3.89\right.$, $P<0.02)$. This effect was due to a later $\mathrm{N} 1 \mathrm{~m}$ response for the $6000 \mathrm{~Hz}$ stimulus, the difference ranging between 6 (compared to $1000 \mathrm{~Hz}$ ) and $8 \mathrm{~ms}$ (compared to 1817 and $3302 \mathrm{~Hz})$.

\subsection{N1m amplitude}

$M$ arked differences between the paradigms were also obtained for the amplitude of $\mathrm{N} 1 \mathrm{~m}$ (see Fig. 1a), which was about 15-20 fT smaller for signals of the bi-mapping ( $M=128.21 \mathrm{fT}, \mathrm{SE} 7.05)$ than for the classic paradigm ( $M=143.55 \mathrm{fT}, \mathrm{SE}$ 7.32) independent of frequency $\left(F_{1,10}=7.51, \quad P<0.03\right)$. Concerning frequency, the $1000 \mathrm{~Hz}$ stimuli yielded the strongest response $(M=156.95 \mathrm{fT}, \mathrm{SE} 10.98)$ and $6000 \mathrm{~Hz}(M=102.36 \mathrm{fT}$, SE 6.90) the weakest, the amplitudes of the other two frequencies lying in between $(1817 \mathrm{~Hz}, M=150.93 \mathrm{fT}$; $3302 \mathrm{~Hz}, M=133.29 \mathrm{fT}$ ). The relative weakness of the response to the $6000 \mathrm{~Hz}$ stimuli led to a significant A N OV A effect of frequency $\left(F_{3,30}=13.64, P<0.001\right)$.

\subsection{SSF phase and amplitude}

The circular $\mathrm{T}^{2}$ statistic revealed strong and widespread differences with a focus over the right hemisphere regardless of the paradigm. Fig. 2a shows the most pronounced difference, which was obtained for the comparison between 1000 and $6000 \mathrm{~Hz}$. Since an a priori hypothesis existed, linear contrast analysis statistics were applied for further analysis (Rosenthal and Rosnow, 1985). This method yields an $F$ - (here, critical $F_{1,33}$ at 0.05 significance level, 4.14) and an effect-size value $r_{\text {contrast }}$ (contrast correlations ranging from -1 to 1 ; positive values showing a trend in the predicted direction). Following lambda-weights for the 4 conditions were chosen: -3 $(6000 \mathrm{~Hz}),-1(3302 \mathrm{~Hz}), 1(1817 \mathrm{~Hz})$ and $3(1000 \mathrm{~Hz})$ indicating a linear decrease in amplitude and a phase advance with increasing carrier frequency (Roß et al., 2000).

A clear linear trend for the predicted direction (both paradigms) could be observed contralateral to stimulation (Fig. $2 b$ and $c$ ). Thus, frequency effects appear to be reflected in changes of phase and amplitude, which is in line with inspection of the time-domain waveforms (see Fig. 1b). Looking at the $F$ - and $r_{\text {contrast-values, the trend was more }}$ pronounced for the classic condition, especially with respect to amplitude.

\subsection{Dipole moment}

Similar to other results reported here, the $6000 \mathrm{~Hz}$ condition showed a pronounced deviance from the other conditions in terms of dipole moment. On this measure (see Table 1) source strengths evoked by a $6000 \mathrm{~Hz}$ stimulus were smaller compared to the strength of sources evoked by stimuli of other frequencies $\left(F_{3,30}=3.85, P<0.02\right)$. However, the difference reached statistical significance only for the comparison $1000 \mathrm{vs} .6000 \mathrm{~Hz}$ of the $\mathrm{N} 1 \mathrm{~m}$, thus resulting in a frequency $\times$ component interaction $\left(F_{3,30}=3.26, P<0.04\right)$. M oreover, dipole moments of the combined condition were smaller than those of the classical 
(a) N1-responses
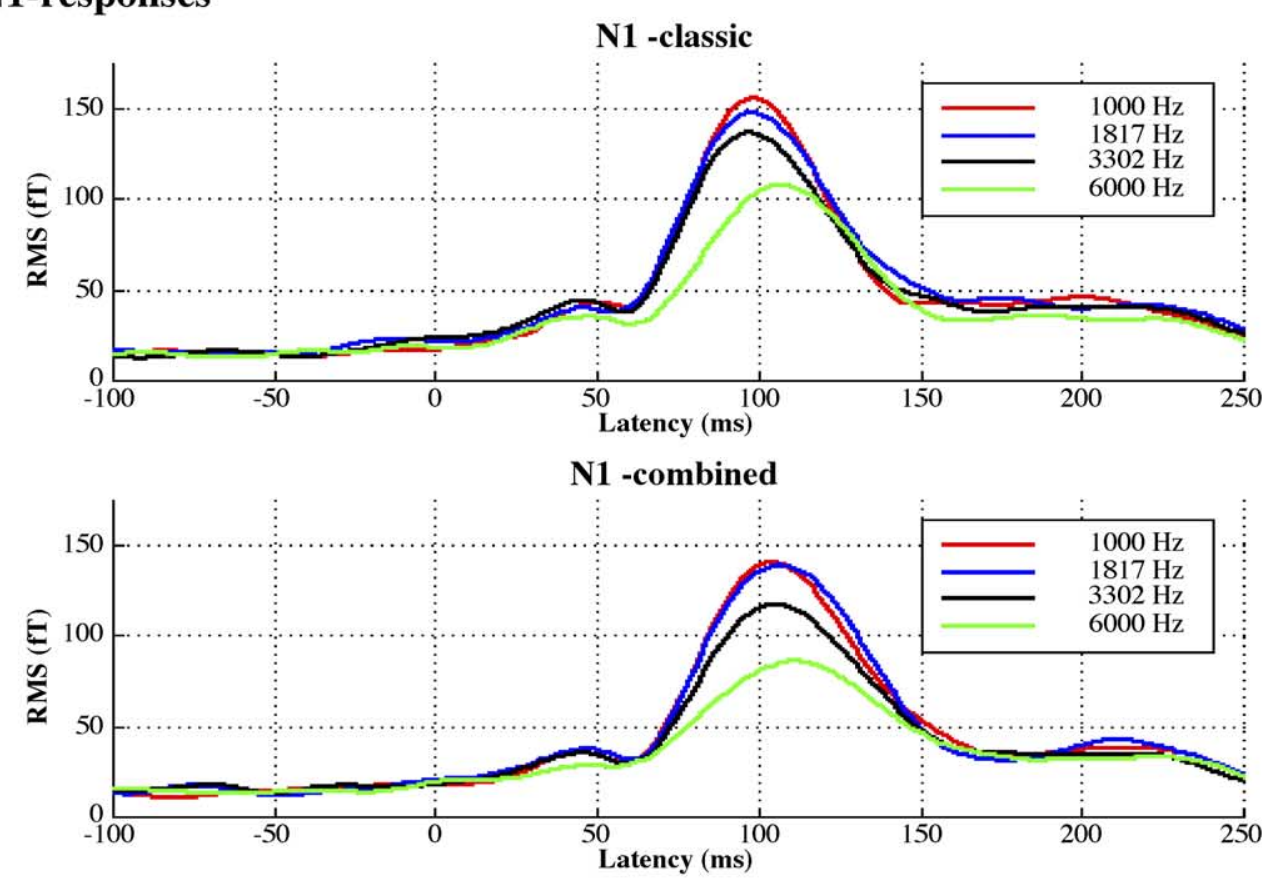

(b) SSF-responses
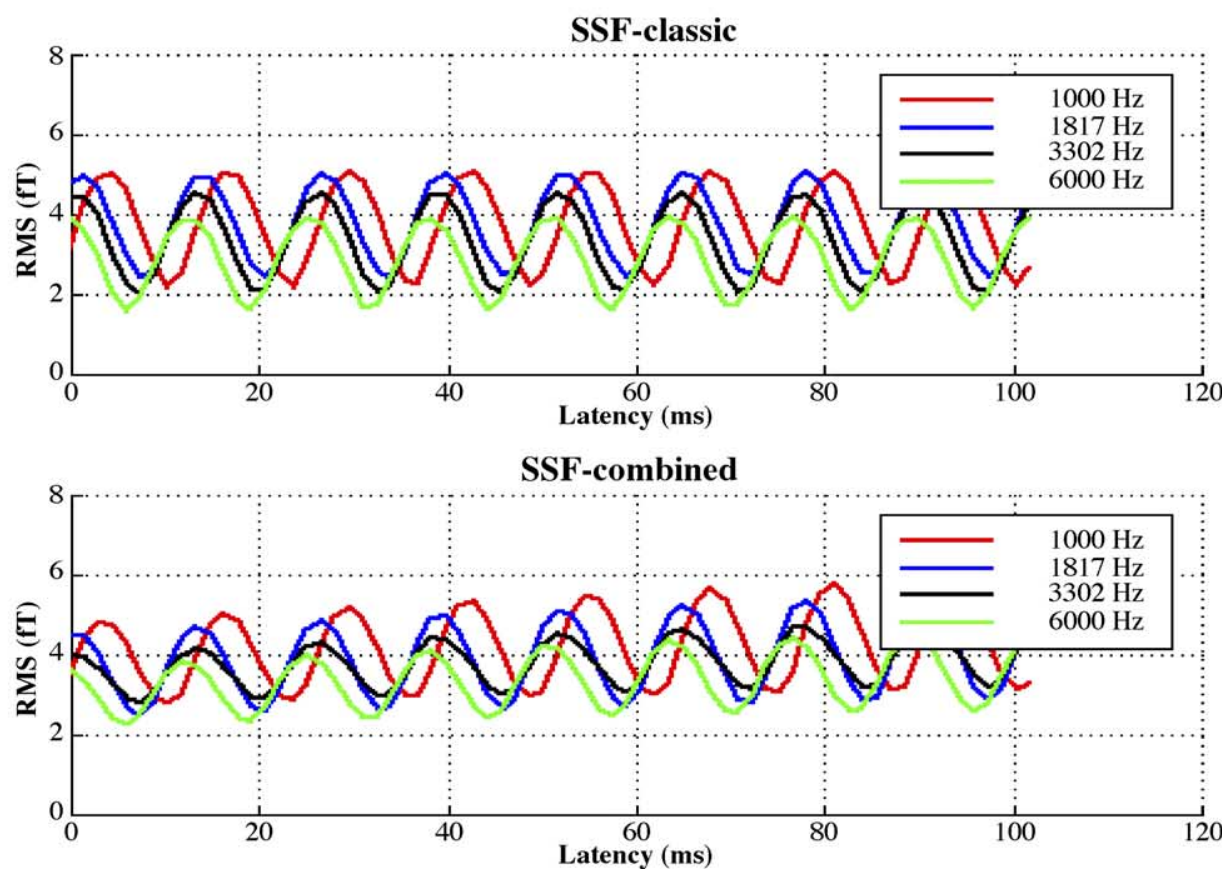

Fig. 1. Grand average waveforms in the signal space for the N $1 \mathrm{~m}$ (a) and SSF (b), derived from the RM S of a 38 sensor group centered over the Sylvian fissure of the right hemisphere.

condition $\left(F_{1,10}=6.91, P<0.03\right)$. A closer inspection showed a reversed pattern of the dipole moment evoked by the two paradigms depending on the component. Post-hoc analysis showed that the paradigm $\times$ component interaction $\left(F_{1,10}=8.96, P<0.02\right)$ is due to the significantly stronger source strength of the classical paradigm in the $\mathrm{N} 1 \mathrm{~m}$ condition.

\subsection{Source localizations}

All results of ECD analysis are depicted in Table 2. Interestingly, a tonotopic gradient was most pronounced on the anterior-posterior axis with higher frequencies being located further towards posterior locations $\left(F_{3,30}=5.82\right.$, $P<0.003)$. Post-hoc analyses indicate that sources evoked 
(a) Circular T ${ }^{2} 1000$ vs. $6000 \mathrm{~Hz}$ (left \& right)

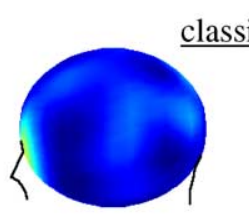

(b) Trend amplitude (right)

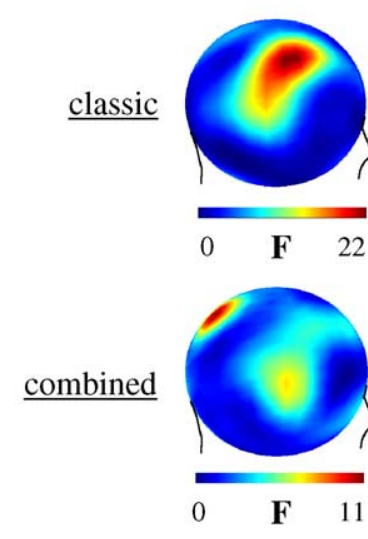

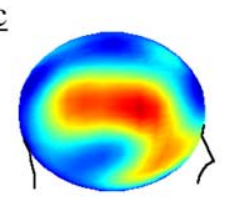
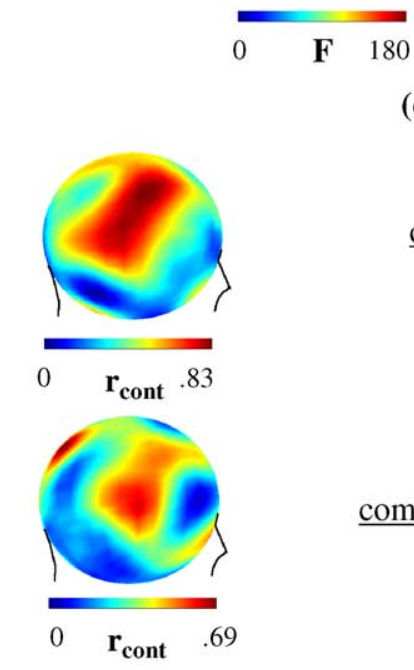

(c) Trend phase (right)
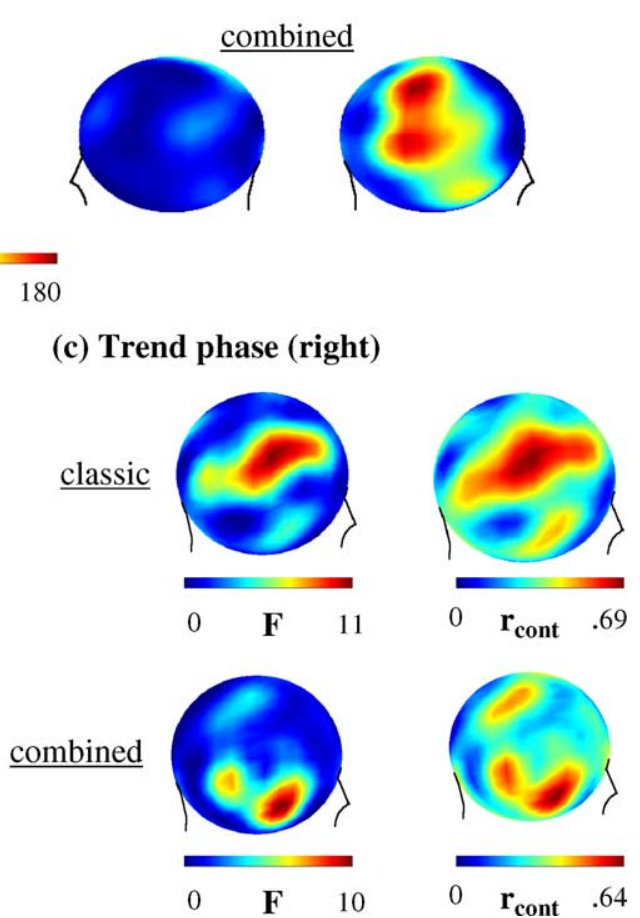

Fig. 2. Statistical analysis of source space projected frequency domain results (pairwise comparisons using the circular $T^{2}$ statistic). (a) $F$-values for the comparison between the 1000 and $6000 \mathrm{~Hz}$ condition for both paradigms. M ultiple comparisons could be summarized using linear contrast analysis yiel ding an $F$ - and effect size map for (b) amplitude and (c) phase.

by $6000 \mathrm{~Hz}$ stimuli were significantly more posteriorally located than sources to 1000 and $1817 \mathrm{~Hz}$. The comparisons 1000 vs. $3302 \mathrm{~Hz}$ (mean difference, $0.34 \mathrm{~cm}$ ) and 1817 vs. $3302 \mathrm{~Hz}$ (mean difference, $0.31 \mathrm{~cm}$ ) approached statistical significance (critical difference, $0.34 \mathrm{~cm}$ ). Concerning the paradigms it can be taken from Table 2 that sources werewith the exception of the SSF elicited by the $6000 \mathrm{~Hz}$ amplitude-modulated tone- consistently more anterior than those from the classical paradigm $\left(F_{1,10}=11.20\right.$, $P<0.01)$. Neither the main effect for the factor, component, nor any interactions were significant (all $F<1$ ), Fig. 3 (left upper panel) shows the localizations collapsed across components overlayed on a standard brain.

In contrast, a tonotopic gradient was not observable for the medial-lateral axes (Fig. 3 upper panel), despite a significant effect for frequency $\left(F_{3,30}=3.19, P<0.05\right)$. As a post-hoc analysis however revealed, this effect was due to a significantly more medial localization of sources evoked during $3302 \mathrm{~Hz}$ stimuli in comparison to $1817 \mathrm{~Hz}$ stimuli. A very stable effect however could be observed for the factor, component: all ECD of SSF were situated further medial than their $\mathrm{N} 1 \mathrm{~m}$ counterparts $\left(F_{1,10}=7.10\right.$, $P<0.05)$. No effects for the factor, paradigm, or interactions were observed (all $F<1$ ).

A s can be taken from Table 2 and Fig. 3 (lower panel), all sources of the SSF components were more superior located than those of the N $1 \mathrm{~m}\left(F_{1,10}=7.28, P<0.05\right)$. However, there was also a dependence of the difference on the factor paradigm, which is indicated by a significant component $x$ paradigm interaction $\left(F_{1,10}=7.47, P<0.05\right)$. A separate A N OV A for each component showed that the SSF-source of the combined paradigm were located superior to the one related to the classical paradigm $\left(F_{1,10}=10.11, P<0.01\right)$.

Overall, the results of ECD analysis suggest distinct representations for the components and the paradigms with

Table 1

A verage dipole strength $(Q)$ for all frequency $\times$ component $\times$ paradigm conditions

\begin{tabular}{lllrl}
\hline Frequency $(\mathrm{Hz})$ & Component & Paradigm & M ean (nA m) & SE \\
\hline \multirow{2}{*}{1000} & N1 & Classic & 28.28 & 2.61 \\
& & Combined & 25.47 & 3.53 \\
& SSF & Classic & 1.02 & 0.14 \\
& & Combined & 1.63 & 0.50 \\
1817 & N1 & Classic & 28.55 & 3.46 \\
& & Combined & 24.97 & 3.26 \\
& SSF & Classic & 0.91 & 0.12 \\
& & Combined & 0.94 & 0.10 \\
3302 & N1 & Classic & 27.75 & 3.22 \\
& & Combined & 25.16 & 4.12 \\
& SSF & Classic & 1.09 & 0.15 \\
& & Combined & 1.20 & 0.13 \\
6000 & N 1 & Classic & 22.93 & 2.96 \\
& & Combined & 16.13 & 1.43 \\
& SSF & Classic & 0.61 & 0.08 \\
& & Combined & 0.80 & 0.14 \\
\hline
\end{tabular}


Table 2

ECD localizations for all frequency $\times$ component $\times$ paradigm combinations

\begin{tabular}{|c|c|c|c|c|c|c|c|c|}
\hline \multirow[t]{2}{*}{ Frequency $(\mathrm{Hz})$} & \multirow[t]{2}{*}{ Component } & \multirow[t]{2}{*}{ Paradigm } & \multicolumn{2}{|c|}{ Posterior-anterior $(x)$} & \multicolumn{2}{|c|}{ M edial - lateral $(y)$} & \multicolumn{2}{|c|}{ Inferior-superior $(z)$} \\
\hline & & & M ean $(\mathrm{cm})$ & SE & M ean $(\mathrm{cm})$ & SE & M ean $(\mathrm{cm})$ & SE \\
\hline 1000 & $\begin{array}{l}\text { N1 } \\
\text { SSF }\end{array}$ & $\begin{array}{l}\text { Classic } \\
\text { Combined } \\
\text { Classic } \\
\text { Combined }\end{array}$ & $\begin{array}{l}1.51 \\
1.54 \\
1.63 \\
1.74\end{array}$ & $\begin{array}{l}0.12 \\
0.15 \\
0.15 \\
0.23\end{array}$ & $\begin{array}{l}-5.24 \\
-5.35 \\
-4.75 \\
-4.62\end{array}$ & $\begin{array}{l}0.24 \\
0.15 \\
0.29 \\
0.12\end{array}$ & $\begin{array}{l}5.50 \\
5.53 \\
5.84 \\
5.96\end{array}$ & $\begin{array}{l}0.19 \\
0.14 \\
0.23 \\
0.34\end{array}$ \\
\hline 1817 & $\begin{array}{l}\text { N1 } \\
\text { SSF }\end{array}$ & $\begin{array}{l}\text { Classic } \\
\text { Combined } \\
\text { Classic } \\
\text { Combined }\end{array}$ & $\begin{array}{l}1.38 \\
1.62 \\
1.42 \\
1.86\end{array}$ & $\begin{array}{l}0.13 \\
0.16 \\
0.23 \\
0.38\end{array}$ & $\begin{array}{l}-5.29 \\
-5.34 \\
-4.93 \\
-4.60\end{array}$ & $\begin{array}{l}0.24 \\
0.16 \\
0.21 \\
0.26\end{array}$ & $\begin{array}{l}5.36 \\
5.42 \\
5.72 \\
5.95\end{array}$ & $\begin{array}{l}0.19 \\
0.19 \\
0.12 \\
0.24\end{array}$ \\
\hline 3302 & $\begin{array}{l}\text { N } 1 \\
\text { SSF }\end{array}$ & $\begin{array}{l}\text { Classic } \\
\text { Combined } \\
\text { Classic } \\
\text { Combined }\end{array}$ & $\begin{array}{l}1.22 \\
1.41 \\
1.17 \\
1.26\end{array}$ & $\begin{array}{l}0.12 \\
0.16 \\
0.27 \\
0.16\end{array}$ & $\begin{array}{l}-5.10 \\
-5.03 \\
-4.17 \\
-4.42\end{array}$ & $\begin{array}{l}0.22 \\
0.31 \\
0.22 \\
0.24\end{array}$ & $\begin{array}{l}5.51 \\
5.28 \\
5.55 \\
5.93\end{array}$ & $\begin{array}{l}0.15 \\
0.18 \\
0.21 \\
0.16\end{array}$ \\
\hline 6000 & $\begin{array}{l}\text { N1 } \\
\text { SSF }\end{array}$ & $\begin{array}{l}\text { Classic } \\
\text { Combined } \\
\text { Classic } \\
\text { Combined }\end{array}$ & $\begin{array}{l}1.09 \\
1.38 \\
1.17 \\
1.08\end{array}$ & $\begin{array}{l}0.13 \\
0.16 \\
0.29 \\
0.30\end{array}$ & $\begin{array}{l}-4.87 \\
-5.24 \\
-4.68 \\
-4.80\end{array}$ & $\begin{array}{l}0.29 \\
0.21 \\
0.31 \\
0.32\end{array}$ & $\begin{array}{l}5.55 \\
5.46 \\
5.42 \\
5.69\end{array}$ & $\begin{array}{l}0.24 \\
0.17 \\
0.32 \\
0.26\end{array}$ \\
\hline
\end{tabular}

Note that more negative values mean further towards the right.

a main tonotopic gradient in the anterior-posterior direction. The SSF is generated more medial $(\approx 5 \mathrm{~mm})$ and more superioral ( $\approx 3 \mathrm{~mm}$, depending on the paradigm) than the $\mathrm{N} 1 \mathrm{~m}$. Sources from the combined paradigm were consistently located more anterior $(\approx 1.6 \mathrm{~mm})$ than those elicited by the classic paradigm. For the purpose of visualization the mean sources collapsed over frequencies was plotted onto a standard brain (average of 24 Talairach transformed brains used in BESA 2000 [MEGIS Software GmbH, Munich, Germany]), which is shown in Fig. 4.

\subsection{Dipole orientation}

The angle of the right-hemispheric N1m-dipole decreased (rotates clockwise) with increasing carrier frequency (see Fig. 5). This is also true for the SSF-dipole orientation derived from the combined condition but contrasted by SSF-classic which produced a counter-clockwise rotation of dipole orientation with increasing carrier frequency. For the results of the combined paradigm, an ANOVA resulted in a significant effect of frequency $\left(F_{3,27}=3.11, P<0.05\right)$. Post-hoc analyses showed that this effect was largely due to a significantly less negative angle for $1000 \mathrm{~Hz}$ as compared to $6000 \mathrm{~Hz}\left(7.33^{\circ}\right.$; critical difference $7.32^{\circ}$ ). The comparison between 1000 and $3302 \mathrm{~Hz}$ approached significance $\left(6.80^{\circ}\right)$.

\section{Discussion}

Compared to other MEG-studies the direction of tonotopy we found is rather unusual, yet not surprising. It is in agreement with the study by Elberling et al. (1982), animal studies (see Kaas et al., 1999) and functional imaging studies (L auter et al., 1985; W essinger et al., 2001). From neuroanatomy it is also known that Heschl's gyrus does not only extend medially, but also in a posterior direction (Talavage et al., 2000). The systematic relationship between the carrier frequency and the dipole
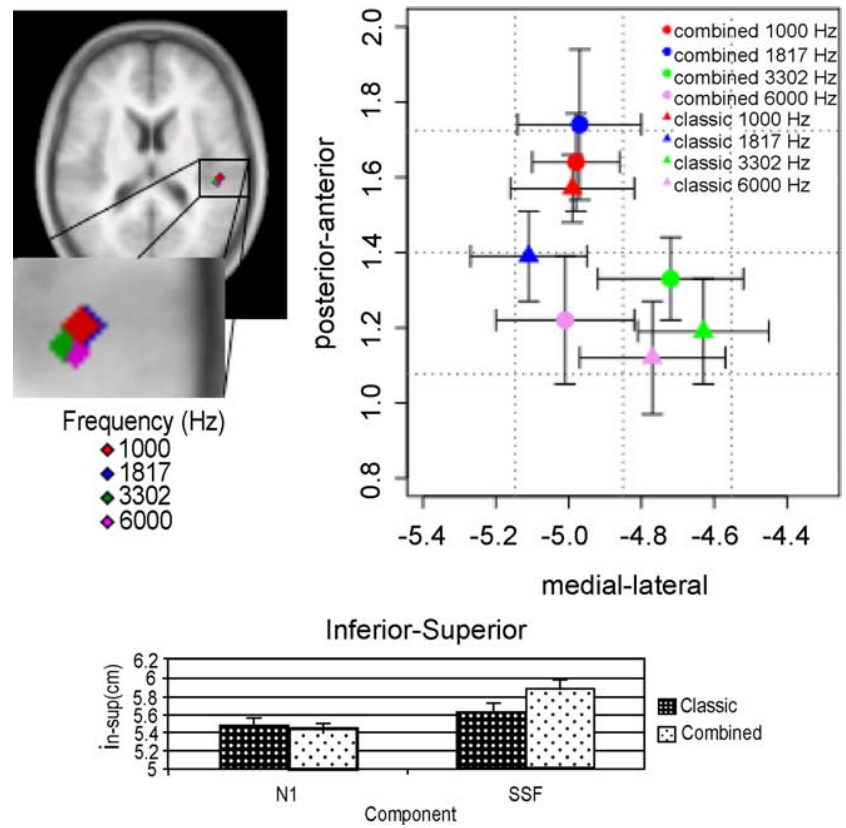

Fig. 3. The upper panel shows source localization on an axial plane. Source localization for the different frequencies is displayed on a standard brain (left upper panel). They are plotted ( $\pm \mathrm{SE}$ ) for the two paradigms separately in the right upper panel (note that more negative values on the $x$-axis indicate locations further to the right). The lower panel displays the location for the components in the inferior-superior direction separately for the two paradigms. 
(a) Coronal

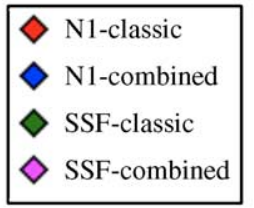

(b) Transversal
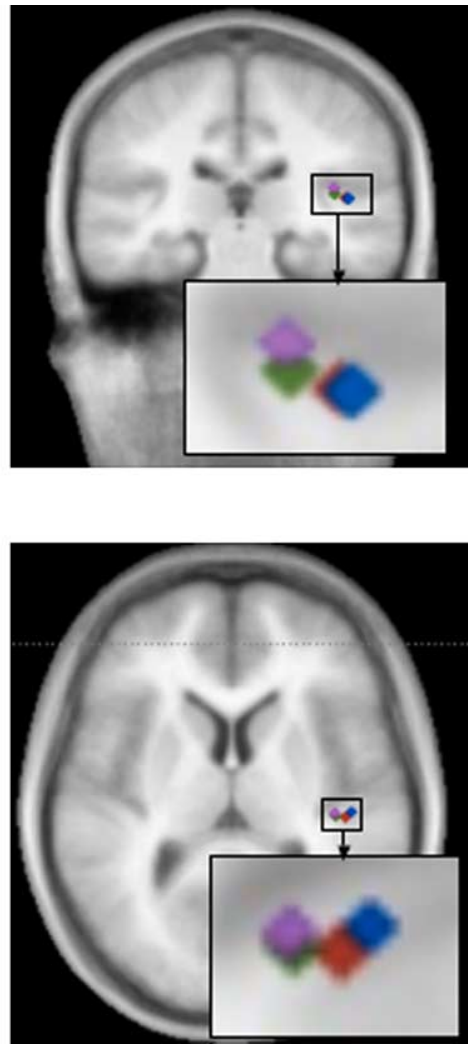

Fig. 4. Overlay of each component $\times$ paradigm condition collapsed over all carrier frequencies.

orientation increases our confidence that tonotopy was assessed. The inability to find a medial - lateral tonotopic gradient, does not indicate that it was generally absent. Several factors might have contributed to this situation. One of them concerns the apparatus employed. Using a magnetometer we cannot exclude the possibility that sensors contralateral to the stimulation measure some ipsilateral activity. This would lead to enhanced variability in the medial-lateral direction. Another point is that assuming a single active neuronal generator at each time point for the sake of localization most surely oversimplifies

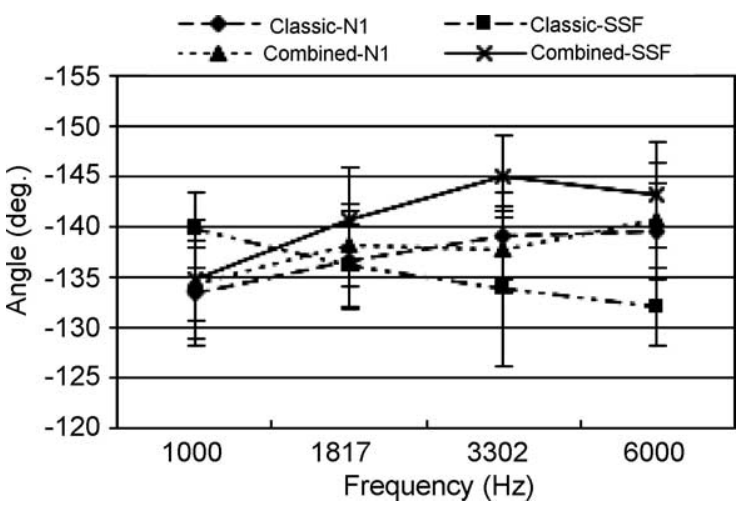

Fig. 5. Dipole orientation in the saggital plane. Increasing negative values correspond to a clockwise movement when viewed from the right side of the brain. the actual soure configuration. In fact there has been some evidence, at least two sources are involved in the generation of both - the N Im (Rogers et al., 1990) and SSF (Gutschalk et al., 1999)-components. This should be kept in mind when interpreting the present results.

The more medial localization of the SSF is in accordance with previous studies (Godey et al., 2001) and gives support to the assumption that the SSF and N $1 \mathrm{~m}$ sources stem from different auditory fields. In addition to this finding, several other aspects of the results replicated across paradigms. Concerning peak latency and amplitude of the N1m, SSF phase, and SSF amplitude, it is interesting that the combined and the classic approaches showed the same pattern of results. Specifically, we replicated the previously reported (Roß et al., 2000) negative relationship between SSF carrier frequency and amplitude/phase.

Next to these parallels however, several systematic differences between the paradigms indicate that the tonotopic maps derived via the two approaches are not entirely the same. These differences were observable for amplitude and latency characteristics of the respective waveforms, with N1m peaking earlier and with higher amplitude in the classic condition. Furthermore the aforementioned amplitude and phase relationships with carrier frequency for the SSF were more pronounced for the classic condition as indicated by higher contrast $F$-values and effect sizes. It has to be mentioned of course that more than twice as many epochs were obtained in the classic than for the combined paradigm. So this difference might be mainly due to a higher signal-to-noise ratio in the classic condition. Certainly, most information concerning the assumption of diverse tonotopic fields are the results of the ECD analysis. For the N 1m, source strengths were largest when elicited by the classic (i.e. pure tone) paradigm. Localization of the ECDs were markedly different for the two paradigms especially in the anterior-posterior direction with sources of the combined paradigm lying consistently further anterior. Based on a sample of our subjects, we can say that localization accuracy for the $\mathrm{N} 1 \mathrm{~m}$ is excellent in the majority of cases with confidence intervals around $30 \mathrm{~mm}^{3}$. This magnitude conforms well with results from a simulation study reported by Gallen et al. (1992). Due to the averaging procedure for the SSF (without baseline) an estimate of confidence intervals is not possible for this component. Taken together with the N 1m-SSF comparison it is possible to speculate that each paradigm $\times$ component combination provokes activity from different auditory fields. At least 3 fields of the auditory cortex-AI and the rostrotemporal field of the core and the middle- lateral field of the belt area-are known to exhibit a low-to-high anterior-posterior gradient as observed in this study (Hackett et al., 2001; K aas et al., 1999). Y et it is unclear to what extent these results mainly gained from investigating macaque brains are applicable to humans. Parametric studies using fMRI and MEG on the same set of subjects, appear to be promising to investigate the question left open 
by our study, that the different conditions elicited activity from different auditory fields, as (a) the amount of auditory fields in humans and also (b) the stimulus features necessary to evoke activity from these fields can be investigated. However, also more trivial al ternatives have to be taken into account. In case of the steady state it is, e.g. conceivable that sources of P2m- (Lütkenhöner and Steinsträter, 1998; Tarkka et al., 1995) and sustained field (SF; M äkelä and Hari, 1987) contributed more to the further anterior lying localization for the combined condition, due to its shorter duration as compared to the classic condition. To conclude, the present study showed that two tonotopic maps could be obtained simultaneously by combining features of standard N Im (evoked field) and SSF paradigms. Very remarkable are the identical patterns of results concerning amplitude and latency/phase characteristics of the components. However, we found significant differences between the combined and the standard N1m and SSF paradigms in contrast to the result of Engelien et al. (2000). A possible explanation concerns the choice of frequencies. In contrast to Engelien et al. who used a low $(250 \mathrm{~Hz})$ carrier frequency, we focused on high carrier frequencies ( $>1000 \mathrm{~Hz}$ ). Following studies should address this question by including additionally lower carrier frequencies. An additional effect would be to have a wider range of octaves than in the present study which might have also contributed to the missing medial - lateral tonotopic gradient. In general, effects were more pronounced when gained via the classic paradigms. As in the case of the SSF this, however, might simply be a result of a smaller signal-tonoise ratio of the bi-mapping paradigm. Even if more trials than presently used are recommended, we consider the design to be of some impact for clinical routine. For instance, it seems ideally suited to study plastic alterations that have been observed in blind individuals (E lbert et al., 2002) or subjects with a hearing loss (M äkelä et al., 2000).

\section{Acknowledgements}

This work was supported by the Deutsche Forschungsgemeinschaft (DFG; EL 101/20).

\section{References}

Ehret G. The auditory cortex. J Comp Physiol 1997;181:547- 57.

Elberling C, B ak C, K ofoed B, Lebech J, Saermark K. A uditory magnetic fields: source location and 'tonotopical organization' in the right hemisphere of the human brain. Scand A udiol 1982;11:61- 5.

Elbert T, Sterr A, Rockstroh B, Pantev C, M üller M, Taub E. Expansion of the tonotopic area in the cortex of the blind. J Neurosci 2002;22: 9941- 4 .

Engelien A, Schulz M, Ross B, A rolt V, Pantev C. A combined functional in vivo measure for primary and secondary auditory cortices. Hear Res 2000;148:153-60.
Galambos R, Makeig S, Talmachoff PJ. A 40- $\mathrm{Hz}$ auditory potential recorded from the human scalp. Proc Natl A cad Sci 1981;78:2643- 7.

Gallen C, Pantev C, Hampson S, Buchanan DS, Sobel D. Reliability and validity of auditory neuromagnetic source localization using a large array biomagnetometer. In: Hoke M, Erné SN, Okada Y, Romani GL, editors. Biomagnetism: clinical aspects. Amsterdam: Elsevier; 1992. p. $171-5$.

Godey B, Schwartz D, de Graaf JB, Chauvel P, Liégeois-Chauvel C. Neuromagnetic source localization of auditory evoked fields and intracerebral evoked potentials: a comparison of data in the same patients. Clin Neurophysiol 2001;112:1850- 9.

Gutschalk A, M ase R, Roth R, Ille N, Rupp A, Hahnel S, Picton TW, Scherg M. Deconvolution of $40 \mathrm{~Hz}$ steady-state fields reveals two overlapping source activities of the human auditory cortex. Clin Neurophysiol 1999;110:856-68.

Hackett TA, Preuss TM, K aas JH. A rchitectonic identification of the core region in auditory cortex of macaques, chimpanzees, and humans. J Comp Neurol 2001;441:197-222.

Hämäläinen M , IImoniemi RJ . Interpreting measured magnetic fields of the brain: estimates of current distributions. Technical Report TKK-FA 559; 1984.

Hari R, Hämäläinen $M$, Joutsiniemi SL. Neuromagnetic steady-state responses to auditory stimuli. J A coust Soc Am 1989;86:1033-9.

Hauk O, K eil A, Elbert T, M üller M. Comparison of data transformation procedures to enhance topographical accuracy in time-series analysis of the human EEG. J Neurosci M ethods 2002;113:111- 22

$\mathrm{K}$ aas JH, Hackett TA, Tramo MJ. A uditory processing in primate cerebral cortex. Curr Opin Neurobiol 1999;9:164- 70.

L auter J L, Herscovitch P, Formby C, Raichle M. Tonotopic organization in human auditory cortex revealed by positron emission tomography. Hear Res 1985;20:199- 205.

Lütkenhöner B, Steinsträter 0 . High-precision neuromagnetic study of the functional organization of the human auditory cortex. A udiol N eurootol 1998;3:191- 213.

Mäkelä JP, Hari R. Evidence for cortical origin of the $40 \mathrm{~Hz}$ auditory evoked response in man. Electroencephalogr Clin Neurophysiol 1987; 66:539- 46.

M äkelä JP, Elbert T, K akigi R, L opez L, Nagamine T, Nakasato N, Sannita W. MEG: clinical applications. In: Aine C, Okada Y, Stroink G, Swithenby $S$, Wood $C$, editors. A dvances in biomagnetism research: Biomag96. New Y ork: Springer; 2000. p. 980-90.

M erzenich M M, Knight PL, Roth GL. Representation of cochlea within primary auditory cortex in the cat. J Neurophysiol 1975;38:231-49.

Pantev C, Elbert T, M akeig S, Hampson S, Eulitz C, Hoke M. Relationship of transient and steady-state evoked fields. Electroencephalogr Clin Neurophysiol 1993;88:389-96.

Pantev C, Roberts LE, Elbert T, Roß B, Wienbruch C. Tonotopic organization of the sources of human auditory steady-state responses. Hear Res 1996;101:62-74.

Pastor M A , A rtieda J, A rbizu J, M arti-Climent J M, Penuelas I, M asdeu J C. Activation of human cerebral and cerebellar cortex by auditory stimulation at $40 \mathrm{~Hz}$. J Neurosci 2002;22:10501- 6 .

Rogers RL, Papanicolaou AC, Baumann SB, Saydjari C, Eisenberg HM. Neuromagnetic evidence of a dynamic excitation pattern generating the N100 auditory response. Electroencephalogr Clin Neurophysiol 1990; 77:237- 40

Romani GL. Tonotopic organization of the human auditory cortex revealed by steady state neuromagnetic measurements. Acta Otolaryngol Suppl 1986; $432: 33-4$

Romani GL, Williamson SJ, Kaufman L. Tonotopic organization of the human auditory cortex. Science 1982a;216:1339- 40.

Romani GL, Williamson S], Kaufman L, Brenner D. Characterization of the human auditory cortex by the neuromagnetic method. Exp Brain Res 1982b;47:381- 93.

Rosenthal R, Rosnow RL. Contrast analysis: focused comparisons in the analysis of variance. Cambridge: Cambridge University Press; 1985. 
Roß B, B orgmann C, D raganova R, Roberts LE, Pantev C. A high-precision magnetencephalographic study of human auditory steady-state responses to amplitude modulated tones. J A coust Soc A m 2000;108: 679- 91.

Rouiller EM . Functional organization of the auditory pathways. In: Ehret G, Eomand R, editors. The central auditory system. New Y ork: Oxford University Press; 1997. p. 3- 96.

Talavage TM, Ledden PJ, Benson RR, Rosen BR, M elcher J R. Frequencydependent responses exhibited by multiple regions in human auditory cortex. Hear Res 2000;150:225-44.

Tarkka IM, Stokic DS, Basile LF, Papanicolaou AC. Electric source localization of the auditory P300 agrees with magnetic source localization. Electroencephalogr Clin Neurophysiol 1995;96: 538- 45.

Tiihonen J, Hari R, K aukoranta E, K ajola M. Interaural interaction in the human auditory cortex. A udiology 1989;28:37- 48.
Tiitinen $\mathrm{H}$, Alho K, Houtilainen $\mathrm{M}$, Ilmoniemi RJ, Simola J, Näätänen R Tonotopic auditory cortex and the magnetoencephalographic (MEG) equivalent of the mismatch negativity. Psychophysiology 1993;30: 537- 40.

Verkindt C, Bertrand 0 , Perrin F, Echallier JF, Pernier J. Tonotopic organization of the human auditory cortex: N100 topography and multiple dipole model analysis. Electroencephalogr Clin Neurophysiol 1995;96:143-56.

Victor DJ, M ast J. A new statistic for the steady-state evoked potential. Electroencephalogr Clin Neurophysiol 1991;78:378-88.

Wallace M N, Johnston PW, Palmer AR. Histochemical identification of cortical areas in the auditory region of the human brain. Exp Brain Res 2002;143:499- 508

Wessinger CM, V anM eter J, Tian B, V an Lare J, Pekar J, Rauschecker JP. Hierarchical organization of the human auditory cortex revealed by functional magnetic resonance imaging. J Cogn N eurosci 2001;13:1- 7. 